\title{
Las garantías procesales de las víctimas en la normatividad de la Unión Europea
}

Fecha de recepción: 15 de febrero de 2019

Fecha de aceptación: 26 de agosto de 2019

Doi: https://doi.org/10.12804/revistas.urosario.edu.co/acdi/a.7686

\section{Angélica María Anichiarico González \\ Cástulo Cisneros Trujillo**}

Resumen: este artículo proporciona una reflexión sobre las garantías procesales de las víctimas en la Unión Europea, a partir del punto de vista de los actores y la forma en que los Estados y la Unión Europea han influido en su normatividad, considerada una de las más protectoras y salvaguardas del mundo. Desde una perspectiva interpretativa, con base en los acontecimientos y la profunda participación, se verá cómo esta normatividad ha demostrado un avance importante en el interés de

* Doctoranda y magíster en estudios avanzados en derechos humanos de la Universidad Carlos III de Madrid y abogada. Docente investigadora y miembro del Grupo de Investigación Interdisciplinar de Ciencias Sociales y Humanas (GIICSH) de la Corporación Universitaria Autónoma del Cauca, Colombia. Correo electrónico: angelica.anichiarico.g@, uniautonoma.edu.co. ORCID: http://orcid.org/0000-0003-1704-1485

** Doctorando y magíster en derecho público de la Universidad Carlos III de Madrid. Magíster en derecho con énfasis en responsabilidad contractual, extracontractual y del Estado de la Universidad Externado de Colombia y abogado especialista en derecho administrativo de la Pontificia Universidad Javeriana. Investigador independiente. ORCID: http://orcid.org/0000-0003-0539-2958Correo electrónico: ferchocisneros@hotmail.com Para citar este artículo: Anichiarico González, Angélica Maríay, \& Cisneros Trujillo, Cástulo, "Las garantías procesales de las víctimas en la normativa de la Unión Europea”. Anuario Colombiano de Derecho Internacional (ACDI) 13, 2020, 251-286. https://doi.org/10.12804/revistas.urosario.edu.co/acdi/a.7686 
proteger y garantizar el derecho a la verdad y la justicia de quienes han sufrido o experimentado las consecuencias de delitos.

Palabras clave: garantías procesales, Unión Europea, verdad, justicia y reparación, víctimas.

The Procedural Guarantees of the Victims in the Regulation of the European Union

Abstract: This article reflects on the victims' procedural guarantees in the European Union (EU), considering the actors' point of view and how the States and the EU have influenced their normativity, considered as one of the most protective and safeguarding in the world. From an interpretative perspective based on the events and deep involvement, this normativity has demonstrated an essential breakthrough in the interest to protect and guarantee the right of truth and justice of those who have suffered or experienced the consequences of crime.

Keywords: Procedural guarantees, European Union, truth, justice and reparation, victims.

\section{As garantias processais das vítimas na normatividade da União Europeia}

Resumo: este artigo proporciona uma reflexão das garantias processais das vítimas na União Europeia, tendo em conta o ponto de vista dos atores e a forma em que os Estados e a União têm influído em sua normatividade, que se considera uma das mais protetoras e salvaguardas do mundo. Desde uma perspectiva interpretativa, com base nos acontecimentos e a profunda participação, veremos como esta normatividade tem demostrado um avanço importante no interesse de proteger e garantir o direito à verdade e à justiça de quem têm sofrido ou experimentado as consequências dos delitos.

Palavras-chave: garantias processais, União Europeia, verdade, justiça e reparação, vítimas. 


\section{Introducción}

La creciente movilidad de los ciudadanos europeos determina un mayor refuerzo de la protección a las víctimas de delitos como respuesta a la necesidad de evidenciar una particular sensibilidad por la defensa y el respeto de sus derechos, más aún si se tiene en cuenta que el foco de atención ha recaído históricamente en la lucha contra la delincuencia y en los derechos y garantías de los imputados. ${ }^{1}$

Por esta razón, resultan necesarios instrumentos normativos que garanticen una protección igualitaria de las víctimas — sobre todo cuando se trata de delitos como la agresión sexual, los tratos inhumanos y degradantes y los menoscabos a la integridad, entre otros- principalmente en el espacio común que constituye la Unión Europea (UE) a partir de los principios de fomento del acceso de las víctimas a la justicia; el refuerzo del derecho de la víctima y su asesor jurídico a recibir información puntual sobre el proceso, y la promoción del recurso a la justicia reparadora y las modalidades alternativas de resolución de conflictos, teniendo siempre en mente sus intereses. ${ }^{2}$

Justamente, el contexto de llevar a la víctima como un actor fundamental en los procesos penales no se ha escapado de la política criminal europea —aunque sorprendentemente es muy reciente—, que permite su ingreso en la normatividad, lo que para algunos ha sido objeto de cuestionamiento puesto que le genera cargas adicionales al imputado o procesado. ${ }^{3}$ No obstante, otros —entre los que se encuentra la Comisión Europea-consideran que la participación del perjudicado puede traer

\footnotetext{
De acuerdo con el Parlamento Europeo aproximadamente cada año se denuncian 30 millones de delitos en la Unión Europea. Cfr. Parlamento Europeo, Informe sobre la aplicación de la Directiva 2012/29/UE por la que se establecen normas mínimas sobre los derechos, el apoyo y la protección de las víctimas de delitos (2016/2328(INI)), 14 de mayo de $2018,3$.

2 Al respecto se puede consultar Marina Sanz-Díez De Ulzurrun Lluch, "La posición de la víctima en el derecho comparado y en la normativa de la Unión Europea", Estudios de Derecho Judicial, no. 121 (2007): 158-159; María José Rodríguez Puerta, "Sistemas de asistencia, protección y reparación de las víctimas", en Manual de Victimología, editado por Enrique Baca Baldomero, Enrique Echeburúa Odriozola y Josep María Tamarit Sumalla, (Valencia: Tirant lo Blanch, 2006), 416.

3 En ese sentido se pronuncia Bernd Schünemann, "Der Ausbau der Opferstellung im Strafprozess -Flucht oder Segen?”, en Festschrift für Rainer Hamm, (Berlín, 2008), 687-700 y 690 y ss.
} 
efectos positivos puesto que elimina daños secundarios ocasionados por la conducta punible. ${ }^{4}$

Actualmente se ha redescubierto a la víctima, quien ha encontrado en el ámbito del Ordenamiento Jurídico de la UE un importante avance en la consagración y consolidación definitiva de la justicia al interior de este territorio. El artículo 82.2 del Tratado de Funcionamiento de la UE (TFUE) establece el marco de armonización procesal con el propósito de facilitar el reconocimiento mutuo de resoluciones en asuntos penales, con dimensión transfronteriza, de tal manera que consagra un conjunto de normas mínimas que unifican materias referentes a los derechos de los procesados o acusados, así como a los de las víctimas. ${ }^{5}$

La Decisión Marco 2001/220/JAI del 15 de marzo de 2001 (a partir de este momento Decisión Marco), relativa al estatuto de la víctima en el proceso penal, constituyó el primer paso de hard law en la creación de un estatuto jurídico para estas y la idea de armonizar la normatividad en dicha materia. Posteriormente, en los últimos años, han ido publicándose un conjunto de directrices con las que se pretende conseguir el deseado equilibrio entre los valores de seguridad y justicia para garantizar un sinnúmero de derechos inviolables a las partes que se vean implicadas en un proceso penal. ${ }^{6}$

La Directiva 2012/29/UE del Parlamento Europeo y del Consejo del 25 de octubre de 2012 (La Directiva), por la que se establecen normas mínimas sobre los derechos, el apoyo y la protección de las víctimas de

4 Stefanie Bock, "Das europäische Opferrechtspaket: zwischen substantiellen Fortschritt und blinden Aktionismus", ZIS 8, (2013): 202; Antony Pemberton, Frans Willem Winkel, y Marc Groenhuijsen, "Taking Victims Seriously in Restorative Justice”, International Perspectives in Victimology 3, no. 1 (2007): 4-14; Nils Christie, "The Ideal Victim," en From Crime Policy to Victim Policy, editado por Ezzat A. Fattah, (London: Palgrave Macmillan, 1986); Montserrat de Hoyos Sancho, "Reflexiones sobre la Directiva 2012/29/UE, por la que se establecen normas mínimas sobre los derechos, el apoyo y la protección de las víctimas de delitos, y su transposición al ordenamiento español", Revista General de Derecho Procesal, no. 34 (2014): 4.

5 En este punto ha sido relevante el papel del Tribunal de Justicia de la Unión Europea. $\mathrm{Al}$ respecto puede consultarse Iván Grigoriev, Role of the European Court of Justice in the Third Pillar: Does Not it Grow Too Fast?, Higher School of Economics, documento de investigación no. WP BRP 11/IR/2014, https://papers.ssrn.com/sol3/papers.cfm?abstract_id=2543443

6 Un análisis detallado del contenido de la Decisión Marco se puede encontrar en Teresa Armenta Deu (Coord.), Código de buenas prácticas para la protección de víctimas especialmente vulnerables, (Madrid: Colex, 2011). 
delitos y se sustituye la Decisión Marco del Consejo, se enmarca en este contexto y responde a la necesidad de reforzar los derechos, el apoyo y la protección a las víctimas de delitos. ${ }^{7}$ Esta norma aporta un efecto más vinculante, preciso y efectivo frente a los Estados pues les impone obligaciones que pueden ser objeto de control mediante el recurso de incumplimiento consagrado en el artículo 258 del TFUE.

Las disposiciones de La Directiva buscan proteger a las víctimas durante el desarrollo del proceso con unos criterios mínimos que pueden ser ampliados por los Estados para aportar soluciones tendentes a evitar la llamada "victimización secundaria" y reconocer un conjunto de derechos y garantías que deben proporcionarse a esta población con el objetivo que reciba información, apoyo y protección adecuada, teniendo en cuenta sus necesidades específicas y la gravedad del daño sufrido, previo y posterior al proceso penal. Adicionalmente, esta se constituyó en un elemento normativo trascendental en aquellos Estados donde la víctima no era reconocida como interviniente en el proceso.

Este marco legal permite que este artículo se centre en exponer e interpretar la normatividad relativa a las garantías procesales de las víctimas en el interior de la UE desde un estudio de los derechos consagrados y establecidos a favor de ellas.

\section{El camino hacia un estatuto de las víctimas en la normatividad europea}

La política criminal en el marco de la libertad, seguridad y justicia consideró, desde el Pacto Internacional de Derechos Civiles y Políticos ${ }^{8}$ y en la década de los 80, la Declaración de Naciones Unidas sobre principios fundamentales de justicia para las víctimas de delitos y de abuso del poder de 1985 la cual contiene un gran número de derechos y servicios entre

Al respecto puede consultarse Gema Varona Martínez, "El impacto de la política victimal de la Unión Europea en el sistema penal español: estudio particular de los efectos reales de la Directiva 2012/29/UE sobre derechos de las víctimas de delitos", en Adaptación del derecho penal español a la política criminal de la Unión Europea, 545-91, (Pamplona: Aranzadi, 2017); Natalia Pérez-Rivas, "El modelo europeo de estatuto de la víctima", Dikaion 26, no. 2 (2017).

8 Adoptado y abierto a la firma, ratificación y adhesión por la Asamblea General en su Resolución 2200 A (Xxi) del 16 de diciembre de 1966. Entrada en vigor el 23 de marzo de 1976, de conformidad con el artículo 49. 
los que se destacan el acceso a la justicia y trato justo, el resarcimiento, la asistencia e indemnización. ${ }^{9}$

Al observar esto, el Consejo de Europa mediante normas soft law comenzó ha desarrollar los derechos de las víctimas. El convenio del 24 de noviembre de 1983 de indemnización estatal a víctimas de delitos violentos tenía como principal objetivo lograr que los Estados europeos adoptaran mecanismos de resarcimiento con cargo a recursos públicos, principalmente, de manera subsidiaria en aquellos casos en los que el condenado por el hecho delictivo y declarado responsable civilmente no pudiera hacerse cargo de la obligación de reparar.

Con posterioridad, el Consejo de Europa emitió la Recomendación 1985/11 del 28 de junio de 1985, referente a la posición de la víctima en el sistema de justicia penal, cuyo objetivo era mejorar la situación de las víctimas y evitar la revictimización o "victimización secundaria", imponiendo modelos que deben seguir las entidades públicas (jueces, tribunales y policía, entre otros) al momento de tener contacto con la víctima de un delito.

Unos años después, en 1999, el mismo órgano colegiado, con la Recomendación N. R (99)19 del 15 de septiembre de 1999 del Comité de Ministros del Consejo de Europa a los Estados miembros sobre mediación en materia penal, exhortó a los Estados a que facilitaran a las personas el acceso a los servicios de mediación, sin vincular a una idea de justicia restaurativa o alguna referencia especial a las víctimas.

Sin embargo, con la Recomendación N. R (2006)8 del Comité de Ministros del Consejo de Europa a los Estados miembros del 14 de junio de 2006 sobre asistencia a las víctimas del delito se da una evolución hacía las necesidades y los derechos de las víctimas pues pasa a considerárselas como toda persona física que ha percibido un daño psíquico o físico, o pérdida económica o sufrimiento emocional producto de una conducta definida como delito por la normatividad de un Estado.

Por su parte, el Tribunal Europeo de Derechos Humanos (TEDH), aplicando la Convención Europea de Derechos Humanos, ha tenido la oportunidad de pronunciarse respecto a los derechos y garantías de las

\footnotetext{
9 Véase Marien Aguilera, "Justicia penal y Unión Europea: un breve balance en clave de derechos", Diario La Ley, no. 8883 (2016): 1; Alejandro López, "Crimen transfronterizo y determinación de la jurisdicción en el espacio de libertad, seguridad y justicia: ¿hacia una nueva normativa sobre resolución de conflictos de ejercicio de jurisdicción penal?", Revista de estudios europeos, no. 71 (2018): 220-233.
} 
víctimas en temas relacionados con la ilegitimidad de leyes de amnistía que impiden el derecho a la justicia de estas; el deber que tienen los Estados de investigar las muertes generadas por parte de órganos independientes; el derecho a la protección penal y a un recurso efectivo en el caso de torturas; el derecho de las víctimas a una vida privada y familiar; el derecho a un juicio justo con la posibilidad de aportar pruebas, y la protección de testigos que puedan sufrir intimidación.

En lo que tiene que ver con la UE, desde el Tratado de Ámsterdam del 2 de octubre de 1997 se ha buscado la protección de las víctimas de los delitos por medio del establecimiento del plan de acción del Consejo y de la Comisión para hacer efectivos los objetivos de dicho tratado sobre el espacio de libertad, seguridad y justicia, otorgándose un plazo de cinco años a partir de la entrada en vigor de dicha norma para estudiar y realizar un análisis comparado de los sistemas nacionales de indemnización a las víctimas. $^{10}$

Aunque en la actualidad la mayoría de los Estados miembros de la UE cuentan con normatividad y herramientas en procura de proteger los derechos de las víctimas, su participación no se encontraba lo suficientemente definida en los sistemas penales de los países miembros. Ello llevó a que, en el caso de la UE, se considerara oportuno elaborar un mínimo de normas dentro de la justicia penal con el fin de armonizar los ordenamientos jurídicos de los Estados miembros, ampliando el contenido de los derechos que tenían reconocidos en sus respectivas legislaciones nacionales. Esto también sucedió con lo que tiene que ver con el derecho penal y con el derecho procesal penal. Infortunadamente, algunos Estados se han opuesto debido a que no están dispuestos a ceder su soberanía en esos aspectos. Si existiera un proceso penal europeo, sin lugar a duda, la condición de las víctimas sería diferente, ${ }^{11}$ por ello ha sido abordado mediante normatividad específica y concreta.

El asunto central en cuanto al papel de las víctimas en los procedimientos penales a escala de la UE fue abordado ampliamente en el

\footnotetext{
10 Plan de acción del Consejo y de la Comisión para hacer efectivos los objetivos del Tratado de Ámsterdam sobre el espacio de libertad, seguridad y justicia presentado al Consejo Europeo de Viena de los días 11 y 12 de diciembre de 1998, punto 51.c.

11 Sobre el tema se puede consultar VV.AA. Hacia la unificación del derecho penal, (México:. INACIPE, 2006); José López Gómez Colomer, "Víctima del delito y Europa", Revista Teoría y Derecho, no. 17, (2015): 100-120.
} 
Consejo Europeo de Tampere del 15 y 16 de octubre de $1999,{ }^{12}$ cuyas conclusiones sirvieron de fundamento para la emisión de la Decisión Marco relativa al estatuto de la víctima en el proceso penal, que significó el primer instrumento internacional sobre este punto, que trajo una mejora sustancial para el reconocimiento de sus derechos, protección y asistencia en el derecho comunitario. ${ }^{13}$

Sin embargo, el tiempo transcurrido desde su aprobación y los avances conseguidos en la creación del espacio de libertad, seguridad y justicia, así como la oportunidad de abordar nuevas cuestiones en el ámbito de los derechos de las víctimas determinaron que la UE planteara la necesidad de revisar y ampliar su contenido, tomando en consideración las conclusiones de la Comisión sobre su puesta en práctica y aplicación en cada uno de los Estados miembros. ${ }^{14}$ Lo anterior fue la principal crítica a esta Decisión Marco, ya que, a pesar de consagrar situaciones referentes a la cooperación intergubernamental, resultaba ineficaz en el sentido práctico dado que dependía en gran medida de la buena voluntad de los Estados miembros. Incluso se consideró como una recomendación, lo

12 El punto 32 de las conclusiones de esta cumbre enuncia: "Habida cuenta de la comunicación de la Comisión, deberían elaborarse normas mínimas sobre la protección de las víctimas de los delitos, en particular sobre el acceso de las víctimas de los delitos a la justicia y sobre su derecho a ser indemnizadas por los daños sufridos, también por lo que respecta a los gastos judiciales. Además, deberán crearse programas nacionales para financiar medidas, tanto públicas como no gubernamentales, de asistencia y protección de las víctimas".

13 La exposición de motivos de la Decisión Marco del Consejo expresaba "4. Conviene que los Estados miembros aproximen sus disposiciones legales y reglamentarias en la medida necesaria para realizar el objetivo de ofrecer a las víctimas de delitos un elevado nivel de protección, con independencia del Estado miembro en que se encuentren. (...) 5. Es importante concebir y tratar las necesidades de la víctima de forma integrada y articulada, evitando soluciones parciales o incoherentes que puedan acarrear una victimización secundaria. (...) 8. Es necesario armonizar las normas y prácticas en lo que respecta al estatuto y a los principales derechos de la víctima, prestando especial atención al respeto de su dignidad, a su derecho a declarar y ser informada, a comprender y ser comprendida, a ser protegida en las diversas fases de las actuaciones y a que se tenga en cuenta la desventaja de residir en un Estado miembro distinto del de la comisión del delito".

14 Josep María Tamarit Sumalla, "La política europea sobre las víctimas de delitos" en Estudios de Victimología. Garantías y derechos de las víctimas especialmente vulnerables en el marco jurídico de la Unión Europea, editado por Monserrat de Hoyos Sancho, 31-47, (Valencia: Tirant lo Blanch, 2013): 38 y ss. 
que fue calificado por algunos autores como un fracaso ${ }^{15}$ puesto que no podía ser invocada por los tribunales nacionales.

Con posterioridad, el Consejo de Europa aprovechó el marco jurídico que en materia penal ofrecía el Tratado de Lisboa ${ }^{16}$ para adoptar una nueva normativa dirigida a establecer normas mínimas sobre los derechos de las víctimas en la UE con las importantes novedades que esta regulación lleva consigo; se aprobó el 10 de junio de 2011 la Resolución 2011/ C187/01, ${ }^{17}$ producto de la cual se expidió la Directiva del Parlamento Europeo y del Consejo 2011/99/UE del 13 de diciembre de 2011 sobre la orden europea de protección. ${ }^{18}$

Por su parte, se hizo necesario formular una propuesta de La Directiva, presentada por la Comisión Europea - COM(2011) 275-y una serie de informes que le acompañan, ${ }^{19}$ en los que se manifiestan dos tipos de problemas que originaron la expedición de esta propuesta. En primera instancia, se consideró que la legislación de la UE emitida hasta el año 2011 era inadecuada para mejorar las condiciones de las víctimas. En segunda, se estableció que los Estados atienden los intereses y necesidades de las víctimas de delitos de manera diferente e incluso incompleta o parcial en lo referente a reconocimiento, respeto, protección, apoyo, acceso efectivo a la justicia, indemnización y reparación.

La Directiva recogía de manera adecuada los preceptos de los derechos de las víctimas establecidos en la Asamblea de la Organiza-

15 Cfr. José Luis Gómez Colomer, "Víctima del delito y Europa", Revista Teoría y Derecho, no. 17, (2015): 103.

16 El artículo 82.2 del TFUE expresa: "2. En la medida en que sea necesario para facilitar el reconocimiento mutuo de las sentencias y resoluciones judiciales y la cooperación policial y judicial en asuntos penales con dimensión transfronteriza, el Parlamento Europeo y el Consejo podrán establecer normas mínimas mediante directivas adoptadas con arreglo al procedimiento legislativo ordinario. Estas normas mínimas tendrán en cuenta las diferencias entre las tradiciones y los sistemas jurídicos de los Estados miembros".

17 Esta resolución establecía un plan de trabajo para reforzar los derechos y la protección de las víctimas, en particular en los procesos penales.

18 Véase Directiva del Parlamento Europeo y del Consejo 2011/99/UE del 13 de diciembre de 2011 sobre orden europea de protección, (DOUE L 33812 de diciembre de 2011, P. 2-38) Considerando no. 5 .

19 Propuesta de Directiva de la Comisión Europea al Parlamento Europeo, al Consejo, al Comité Económico y Social Europeo y al Comité de las Regiones, por la que se establecen normas mínimas sobre los derechos, el apoyo y la protección de las víctimas de delitos, Bruselas 25 de mayo de 2011. $\operatorname{COM}(2011) 275$ final. 
ción de Naciones Unidas en 1985 y las recomendaciones del Comité de Ministros del Consejo de Europa formulada en el año 2006. A su vez, La Directiva generó una instrucción a todos los países miembros de la UE de adecuar la normatividad interna con plazo máximo antes del 16 de noviembre de $2015 .{ }^{20}$

Por otro lado, adoptaba las necesidades de las víctimas en todas las etapas del proceso, con el fin de recuperarse de las consecuencias del delito, de tal manera que mediante La Directiva en la UE se establecieron situaciones mínimas dirigidas a solventar las necesidades de las víctimas, las cuales son el trato profesional (esto quiere decir que debe ser respetuoso por todas aquellas personas que intervengan dentro del proceso penal, teniendo en cuenta los derechos y necesidades de los más vulnerables); ${ }^{21}$ acceso a la justicia; protección y apoyo (evitando la doble victimización y buscando la asistencia en diferentes situaciones), y la compensación y reparación con el fin de lograr que las víctimas recuperen el lugar en que se encontraban con anterioridad a la comisión del delito independientemente del tipo de delito, aunque la UE ha entendido que algunos casos requieren tratamiento específico. ${ }^{22}$

Como se puede evidenciar, toda esta evolución de la normatividad respecto de las víctimas en la UE en ningún caso puede ser entendida como una iniciativa aislada al interior de esta, pues es una necesidad concatenarla con la construcción y perfeccionamiento del espacio de libertad, seguridad y justicia, y de modo más general con la evolución en el reconocimiento y

20 A modo de ejemplo, en el caso de España se vio reflejado este punto con la expedición de la Ley 4 de 2015. No obstante, para septiembre de 2017, 23 de los 27 Estados miembros habían incorporado a sus ordenamientos jurídicos nacionales La Directiva, y la Comisión había iniciado dieciséis procedimientos de infracción contra los Estados miembros que todavía no se conforman del todo en la práctica a La Directiva. Cfr. Parlamento Europeo. Informe sobre la aplicación de la Directiva 2012/29/UE.

21 Aunque no existe definición sobre este tipo de víctimas en La Directiva, existen disposiciones que los referencian. Sobre este punto se puede consultar M de Hoyos Sancho, "El tratamiento procesal de las víctimas especialmente vulnerables en los últimos instrumentos normativos aprobados en la Unión Europea" en Garantías y derechos de las víctimas especialmente vulnerables en el marco jurídico de la Unión Europea, editado por Montserrat de Hoyos Sancho, (Valencia: Tirant lo Blanch, 2013), 49-74.

22 Al respecto se puede ver la Directiva 2011/36/UE del 5 de abril de 2011, relativa a la prevención y lucha contra la trata de seres humanos y a la protección de las víctimas o la Directiva 2011/92/UE del 13 de diciembre de 2011, relativa a la lucha contra los abusos sexuales y la explotación sexual de los menores y la pornografía infantil. 
protección de los derechos y libertades fundamentales de los ciudadanos y su proyección en el proceso penal.

\section{Los derechos de las víctimas relacionadas con el proceso penal en la normatividad europea}

Si bien es cierto que la normatividad europea demostraba la voluntad de iniciar políticas referentes a la protección de las víctimas, Europa necesitaba dar el paso hacía un conjunto de condiciones mínimas que debían establecer los ordenamientos jurídicos internos de los países, encaminadas a materializar la importancia que tienen las víctimas. Esto se puede observar con mayor claridad en el Tratado de Lisboa. En este, la UE incorporó una mayor dimensión en la cooperación judicial en materia penal y la disposición expresa de adoptar normas mínimas referentes a los derechos de las víctimas.

A pesar de que para algunos autores como Félix Vacas la Decisión Marco estableció diversas medidas dirigidas a asistir a las víctimas en el entendido de encontrarse dentro del proceso penal y encaminadas a evitar mayores perjuicios del delito, ${ }^{23}$ se encontró que La Directiva planteaba un reconocimiento con mayor desarrollo de los derechos de las víctimas de delitos puesto que contiene un concepto más amplio que el contemplado en la Decisión Marco. Abarca no solo el daño o perjuicio físico generado por el sujeto directo de la conducta punible, sino también a los familiares ${ }^{24}$ de la persona cuya muerte fuera causada por un delito y haya sufrido un daño o perjuicio como consecuencia de esa muerte, siguiendo el criterio establecido en otras normas europeas, que adquieren la condición de víctima indirecta.

En ese entendido, La Directiva contiene un ámbito de aplicación mucho más amplio y extenso del que se venía aplicando. ${ }^{25}$ En todo caso,

23 Félix Vacas Fernández, El terrorismo como crimen internacional, (Valencia: Tirant lo Blanch, 2011), 289.

24 Con arreglo al artículo 1.b) de la Directiva, se entenderá por familiares: "El cónyuge, la persona que convive con la víctima y mantiene con ella una relación personal íntima y comprometida, en un hogar común y de manera estable y continua, los familiares en línea directa, los hermanos y hermanas, y las personas a cargo de la víctima”.

25 El artículo 2.1.a) de la Directiva 2012/29/UE define a la víctima como "la persona física que haya sufrido un daño o perjuicio, en especial lesiones físicas o mentales, daños emocionales o un perjuicio económico, directamente causado por una infracción penal", 
se está de acuerdo con lo que expresa Mercedes Llorente Sánchez-Arjona, quien afirma que esta definición resulta más restrictiva que la prevista en el derecho internacional, principalmente la establecida por la Declaración sobre Principios Fundamentales de Justicia para las Víctimas de Delitos y Abuso de Poder aprobada por la Resolución 40/34 de la Asamblea General de las Naciones Unidas, ya que la misma no contiene sujetos que podrían considerarse como víctimas, tal es el caso de las denominadas víctimas indirectas. ${ }^{26}$

En el mismo sentido se pronuncia Montserrat de Hoyos Sancho, ${ }^{27}$ para quien este tipo de perjudicados solo podrían ser incluidos en el caso de fallecimiento, además de excluir otro tipo de conductas punibles. ${ }^{28}$ Adicionalmente, otro aspecto que ha sido objeto de críticas es la exclusión de la protección en cuanto a las personas jurídicas, ${ }^{29}$ quienes también pueden ser víctimas de delitos, aspecto que venía desde la Decisión Marco y que fue confirmado por el Tribunal de Justicia de la Unión Europea (TJUE) en el Caso Dell'Orto ${ }^{30}$ y el Caso Eredics ${ }^{31}$. Estos puntos deben ser ampliados por los Estados al momento de emitir las leyes de trasposición, ${ }^{32}$ otorgándose la libertad de decidir su inclusión y con qué

con independencia de si se ha procedido a identificar, detener, acusar o condenar al victimario, así como del país europeo en que resida.

26 Mercedes Llorente Sánchez-Arjona, "Las víctimas en el espacio judicial europeo: estudio de la directiva 2012/29/UE, de 25 de octubre de 2012", Revista de Estudios de la Justicia, no. 22 (2015): 130.

27 De Hoyos Sancho, "Reflexiones sobre la Directiva 2012/29/UE...”, 13.

28 Cfr. Silvia Pereira Puigvert, "Normas mínimas para las víctimas de delitos: análisis de la Directiva 2012/29/UE. Especial referencia al derecho de información y apoyo", en Revista General de Derecho Europeo, no. 30, 2013. p. 8.

29 De Hoyos Sancho, "Reflexiones sobre la Directiva 2012/29/UE...", 13.

30 TJuE. Caso Dell'Orto. Sentencia del 28 de junio de 2007. Asunto C-467/07.

31 TJUE. Caso Eredics. Sentencia del 21 de octubre de 2010. Asunto C-205/09.

32 Cabe aclarar que la mayoría de los Estados miembros de la UE incluyen el concepto víctima en su legislación, y proporcionan una definición. Véase Asociación Portuguesa de Apoyo a las Víctimas (APAV), IVOR Report: Implementing victim orientated reform of the criminal justice system in the European Union, Lisboa, 2016, documento cofinaciado por el Programa "Justicia penal" de la UE, 110 y ss. https://www.apav.pt/ivor/images/ivor/PDFs/IVORRepot-WebVersion.pdf 
requisitos puesto que los intereses entre todos estos sujetos resultan ser parecidos en cuanto a información y reparación. ${ }^{33}$

Por ello es importante hacer énfasis en que La Directiva establece unos derechos mínimos a las víctimas con el propósito de dar una mejor respuesta a sus necesidades en el proceso penal, que determinan las garantías procesales de los afectados por el delito. De acuerdo con el análisis de las disposiciones normativas se puede enunciar el derecho a la información, participación, reparación, indemnización, protección y apoyo.

Bajo ese entendido y con el recuento de las directrices principales, las cuales son presupuestos mínimos que pueden ser objeto de una protección más amplia de los Estados, se procede a analizar lo referente a los derechos de las víctimas en el marco de la normatividad europea, tomando como estructura la titularidad de las víctimas sobre los derechos básicos en el marco del proceso penal.

\subsection{Derecho a la información}

Este derecho es de doble vía. Por un lado, el procesado tiene la potestad de conocer cuáles son sus facultades al interior del proceso como el desarrollo del debido proceso y defensa. ${ }^{34}$ Por su parte, lo atinente a los perjudicados se encuentra regulado por los artículos 4 a 6 de La Directiva, que buscan garantizar que las víctimas puedan recibir la información suficiente sobre los derechos que les corresponden para poder ejercerlos de forma efectiva dentro del proceso penal, facilitándoles a su vez el ingreso a los servicios de apoyo, en un lenguaje sencillo y accesible. ${ }^{35}$

Esta información será otorgada por la autoridad que corresponda de acuerdo con el procedimiento o requerimiento propio de la víctima; la definición de competencias o atribuciones es autónoma de cada Estado. Por regla general, se tiene contacto inicial con las autoridades policiales o judiciales, quienes deben prestarle asistencia y comunicarle mediante

\footnotetext{
33 Cfr. de Hoyos Sancho, “Reflexiones sobre la Directiva 2012/29/UE...”, 14.

34 En ese sentido se pronuncia el TEDH. Caso Conka c. Bélgica, sentencia del 5 de febrero de 2002, par. 50. Al respecto se puede consultar Valentina Faggiani, "El derecho a la información en los procesos penales en la UE: la Directiva 2012/13/UE, de 22 de mayo de 2012", Revista General de Derecho Procesal, no. 30, (2013): 1-18.
}

35 Artículo 3.2. de la Directiva 2012/29/UE. 
un lenguaje sencillo, facilitando la interpretación gratuita, el mecanismo con que estas cuentan en procura de hacer valer sus derechos.

La información que le sea facilitada a la víctima determinará la atención a sus necesidades específicas, sus circunstancias personales, el tipo de delito sufrido y la fase en que se halle el procedimiento, situación que le permitiría ejercer sus derechos de manera adecuada y conveniente para satisfacer sus intereses y ejercer efectivamente sus derechos.

Sin embargo, aunque el artículo 5 de la Recomendación 2006/8 establecía como norma mínima en el caso de servicios de apoyo a las víctimas proporcionar la información sobre sus derechos y los servicios disponibles, la evaluación del impacto de la propuesta de La Directiva ${ }^{36}$ - a partir de estudios y encuestas, presentada por la Comisión Europeadeterminó que las víctimas eran ignoradas o no contaban con la información suficiente sobre el proceso judicial, lo que debe considerarse como un requisito previo para que las necesidades de la víctima estén claramente identificadas y atendidas. ${ }^{37}$

Adicionalmente, la manera como los Estados han asegurado que la víctima reciba toda la información ha sido mediante publicaciones en páginas web y la distribución de folletos, herramientas que por sí solas no cumplen con las expectativas de las víctimas, puesto que la protección de sus intereses se logrará con una actitud proactiva de las autoridades. No todo el mundo tiene acceso a internet ni tampoco se puede garantizar que los perjudicados conozcan que la información se encuentra disponible. ${ }^{38}$

Por otro lado, La Directiva en su artículo 6 también le garantiza a la víctima, si esta lo solicita, recibir sin retraso información sobre el curso del proceso penal, que comprenderá diferentes circunstancias procesales como la decisión de no iniciar o poner fin a la investigación o de no procesar al infractor; hora y lugar del juicio y naturaleza de los cargos contra el infractor; sentencia firme o notificación que le permita conocer la situación de su causa, o del hecho de que la persona inculpada

36 Comunicación de la Comisión al Parlamento Europeo, al Consejo, al Comité Económico y Social Europeo y al Comité de las Regiones Refuerzo de los derechos de las víctimas en la UE del 18 de mayo de 2011, COM(2011) 274 final.

37 Ibíd.

38 Susana Oromí I Vall-Llovera, "Víctimas de delitos en la Unión Europea. Análisis de la Directiva 2012/29/UE”, Revista General de Derecho Procesal, no. 30 (2013): 6. 
o condenada haya sido puesta en libertad o se haya fugado, así como de cualquier medida pertinente adoptada para su protección. ${ }^{39}$

También se logró demostrar que infortunadamente la víctima no contaba con los medios para conocer en qué etapa se encontraba su proceso en la mayoría de los Estados de la UE, ${ }^{40}$ de tal manera que la nueva norma buscó imponer como mínimo de garantía a favor de las víctimas la información correspondiente al curso del proceso. En algunos Estados, los procedimientos son relativamente detallados - por ejemplo, Estonia, Irlanda, Finlandia_-, mientras que en otros La Directiva se ha transpuesto textualmente - Italia, Malta- o se ha declarado el derecho, pero no se han proporcionado detalles sobre el procedimiento - Bulgaria, Lituania- Es menos claro cómo se cumple este derecho en la práctica, lo que significa que estos países corren el riesgo de no cumplir con la aplicación de La Directiva.

A su vez, como no se impusieron condiciones para el suministro de información, los mecanismos de activación para informar a la víctima varían. En el Reino Unido, se ha introducido una tarjeta de atención a las víctimas para permitirles a estas y las autoridades pertinentes realizar un seguimiento de un caso con facilidad a medida que avanza a través de las diferentes etapas. Por su parte, dos Estados miembros - Chipre, Eslovenia- parecen no haber transpuesto el artículo 6, y otros tres solo lo han transpuesto parcialmente - Alemania, Luxemburgo, Polonia-.

Además, es fundamental el reconocimiento expreso que hace La Directiva al derecho que tienen las víctimas cuando no entiendan o no hablen la lengua empleada en el proceso penal, producto de lo que se consideró en la propuesta, que en su momento expresó: "Las víctimas también deben poder entender la información recibida y los procedimientos, por lo que es importante poner a disposición traductores e intérpretes, así como información en varios idiomas" (traducción libre). ${ }^{41}$

Cabe resaltar que en el año 2011 solo en 15 de los Estados miembros se encontraban disponibles para la totalidad de las víctimas y no

\footnotetext{
39 Artículo 6 de la Directiva 2012/29/UE del 25 de octubre de 2012. Algunos autores resaltan la exhaustividad de la norma. Al respecto puede consultarse Pereira Puigvert, "Normas mínimas para las víctimas ...", 15.

40 Justamente la Comisión encontró que frente a la facultad de traducción en 27 Estados se contaba con este servicio sin costo alguno y en 6 la información podía ser obtenida en diferentes idiomas.

$41 \operatorname{COM}(2011) 274$ final, 12.
} 
contaban con la suficiente efectividad, ${ }^{42}$ aspecto que desgraciadamente no ha cambiado, ${ }^{43}$ muy a pesar de que todos los Estados miembros han transpuesto el artículo 7 de La Directiva y que se ha incluido el uso del braille o medidas especiales con respecto a las personas con problemas de audición o deficiencias en el habla como en Chipre, o la posibilidad de interpretación remota, generalmente en casos excepcionales, en lugar de que el intérprete esté físicamente presente como en España, Finlandia e Italia. El derecho de acceso a la interpretación o traducción gratuita no siempre se especifica explícitamente tal como sucede en Bulgaria, Estonia, Lituania, Reino Unido (salvo Escocia) y Eslovaquia.

En ese entendido, la normativa de la UE está dirigida a consagrar diversas garantías a favor de las víctimas en lo relacionado a la información que deben recibir y a la que tienen derecho en el desarrollo del proceso penal. No obstante, lo trascendental de la normatividad se deberá ver reflejado en la forma en que cada Estado miembro adopta en sus ordenamientos jurídicos las prerrogativas descritas; sin el concurso de su participación, nuevamente se incurriría en lo que ya sucedió con la Decisión Marco. A su vez, desde el interior de las instituciones de la UE se requiere un monitoreo permanente de cada uno de los Estados para determinar si efectivamente la normatividad está cumpliendo sus objetivos. Si no está sucediendo esto, se deberá proceder con los llamados de atención que correspondan para que los Estados actúen de conformidad con lo ordenado.

\subsection{Participación en el proceso penal}

La normatividad de Europa ha considerado pertinente otorgar a las víctimas un papel trascendental en el proceso penal como desarrollo de las obligaciones adquiridas por parte de los Estados de investigar y

\section{Ibíd.}

Como producto de lo determinado por la propuesta se reprodujo el artículo 7 de La Directiva. Cabe aclarar que el derecho a la información por parte de las víctimas de alguna manera es renunciable, eso es lo que puede entender del análisis del artículo 6.4. de La Directiva: " 4 . El deseo de las víctimas de recibir o no información será vinculante para las autoridades competentes, a menos que sea obligatorio facilitar esa información en virtud del derecho de la víctima a participar de manera activa en el proceso penal. Los Estados miembros permitirán a las víctimas cambiar de opinión al respecto en cualquier momento, y tendrán en cuenta dicho cambio".

$43 \mathrm{Al}$ respecto se puede consultar Parlamento Europeo. Informe sobre la aplicación de la Directiva 2012/29/UE. 
sancionar las graves violaciones a los derechos humanos, al punto que se puede afirmar que actualmente se trata de un tercer actor. Esta afirmación genera serias dificultades puesto que se pueden llegar a afectar puntos elementales frente al juicio justo que debe tener el acusado, que afectan su derecho a la presunción de inocencia e incluso a la igualdad de armas al momento de presentar el material probatorio ${ }^{44}$ dado que pueden formular interrogatorios o incluso presentar documentos buscando la condena del acusado.

En ese caso, para evitar esta dicotomía y dificultad, se debería otorgar a la víctima la posibilidad de constituirse en parte acusadora en el proceso penal, ${ }^{45}$ situación que normalmente no se da en los países, toda vez que el ejercicio de la acción penal es una facultad exclusiva y monopolio del Estado. No obstante, La Directiva no obliga a los Estados a imponer en su normatividad interna un trato equivalente al de las partes en el proceso penal, de tal manera que se constituye en un mero interviniente dentro del proceso. ${ }^{46}$

La Comisión Europea al momento de determinar las necesidades de las víctimas, consideró que las mismas no cuentan con un acceso efectivo a la justicia (traducción libre). ${ }^{47}$ Sin embargo, esta encontró que frente al derecho de revisión de la decisión de enjuiciamiento seis Estados no contaban con este derecho, 21 tenían institucionalizada esta posibilidad y en 25 las víctimas tenían derecho a participar con la asistencia de un abogado.

44 John Vervaele, "El espacio de libertad, seguridad y justicia" en Estudios de Victimología. Garantías y derechos de las víctimas especialmente vulnerables en el marco jurídico de la Unión Europea coordinado por Monserrat de Hoyos Sancho, 15-30, (Valencia: Tirant lo Blanch, 2013), 21. También puede consultarse Valsamis Mitsilegas, Jorge Monar, y Wyn Rees, The European Union and Internal Security. Guardian of the People?, (Londres: Palgrave Macmillan, 2003); Valsamis Mitsilegas, EU Criminal Law, (Oxford: Hart publishing, 2009), 115 y ss.; Anne Weyembergh, "The Functions of Approximation of Penal Legislation within the European Union", Maastricht Journal of European and Comparative Law 12, no. 2 (2005): 149-172; Mar Jimeno Bulnes, "Perspectiva actual del espacio judicial europeo en materia civil y penal: Especial incidencia de la jurisprudencia del Tribunal de Justicia”, en Nuevas aportaciones al espacio de libertad, seguridad y justicia hacia un derecho procesal europeo de naturaleza civily penal, 1-46, (Granada: Comares, 2014).

45 En el mismo sentido se pronuncia Oromí I Vall-Llovera, "Víctimas de delitos en la Unión Europea...", 11.

46 Véase TJuE. Sentencia del 15 de septiembre de 2011. Asunto C-483/09 y C-1/10.

$47 \operatorname{COM}(2011) 274$ final, 2. 
Como producto de estos estudios, La Directiva en su capítulo III enuncia los derechos de participación en el proceso penal, en la que algunos son absolutos tal como ser oídos y presentar las pruebas; revisar la decisión de no continuar el procedimiento; recibir información sobre el proceso, y otros derechos si dependen del sistema nacional y está sometido a las condiciones que establezcan las legislaciones internas.

El derecho a ser oído se desarrolla en dos vertientes. Por un lado, otorgando audiencia a la víctima y, por otro, garantizándole la posibilidad de presentar pruebas durante el proceso. Este derecho es fundamental puesto que es una forma de legitimar el derecho de defensa, contradicción e igualdad de la víctima, situación que impide una revictimización. Mas, en algunos Estados miembros la facultad acusadora se reserva en cabeza de la entidad pública correspondiente, situación que está acorde a La Directiva, puesto que una cosa es el derecho a ser oído y otra el derecho a ser parte del proceso penal. Lo importante es que los Estados permitan a la víctima la posibilidad de ser oída no solo en el marco del proceso penal, sino también en cualquier otra actuación que tenga relación con ella.

A modo de ejemplo, se encontró que el derecho de asistencia y el derecho de participación están sujetos al juez que preside, quien puede limitar dicha participación como en República Checa, a múltiples derechos a nivel procesal durante un juicio penal (Estonia), al uso de declaraciones formales ya sean específicas de una queja o sobre la cuestión del impacto general en la víctima (Irlanda). También hay casos donde los Estados han incluido disposiciones que exceden las de La Directiva como Bélgica y el Reino Unido. En Bélgica, las víctimas tienen derecho a proporcionar cualquier información o documentación que consideren relevante o que pueda agregar a su caso. En el Reino Unido, el desarrollo de una declaración de víctimas les permite proporcionar información sobre cómo les ha afectado el crimen tanto oralmente (ante el jurado), como por escrito (para incluirlas en el registro). Por otro lado, el derecho a ser escuchado no ha sido descrito expresamente en la legislación de Alemania, Luxemburgo ni Malta.

Respecto a la revisión del sobreseimiento de la causa, que consiste en la posibilidad que tiene la autoridad judicial de suspender el proceso por falta de pruebas o por algún otro factor, esta deberá ser notificada a las víctimas directas e indirectas y al denunciante de cuya identidad y dirección se tenga conocimiento por parte de la autoridad judicial, brin- 
dándose la oportunidad a la víctima de recurrir dicha decisión, de acuerdo con la normatividad de cada país. ${ }^{48}$

La mayoría de los Estados miembros han transpuesto este punto de La Directiva, aunque en Estonia y Croacia, la transposición de este derecho no es clara. Al respecto, algunos Estados solo permiten un proceso de notificación y faltan detalles sobre el enfoque exacto para una revisión de la decisión — por ejemplo, en la República Checa o Finlandia-. En otros que han transpuesto este derecho los ejemplos incluyen la capacidad de las víctimas para presentar una queja ante el Fiscal Superior — Suecia-. En algunos países existen otras medidas correctivas como convocar al infractor a los tribunales directamente por delitos menores - Bélgica-. Se considera relevante que este punto sea unificado con un término específico para presentarse la solicitud y resolverse porque las diferencias establecidas en los diferentes Estados generan confusión en las víctimas.

Adicionalmente, en aquellos casos donde la víctima resida en un país diferente, se podrá adelantar la diligencia, inclusive con el desarrollo de medidas alternativas como realizar videoconferencias, tomando como base el Convenio relativo a la asistencia judicial en materia penal entre los Estados miembros de la UE. ${ }^{49}$ Incluso la víctima podrá interponer la denuncia en el Estado de residencia en caso de no poder hacerlo en aquel donde se haya cometido el delito. Para esta participación dentro del proceso penal, ella podrá nombrar un abogado de su confianza o en aquellos casos en que califique para obtener una asistencia judicial gratuita, ${ }^{50}$ se le nombrará uno de oficio, dependiendo de si el Estado prevé que la víctima tenga la calidad de parte en el proceso penal. ${ }^{51}$

Infortunadamente, el acceso a asistencia judicial ha sido limitado en algunos Estados, imponiendo el requisito de tener el estatus legal de residente en la UE — este es el caso de Hungría, Suecia y Grecia-, excluyéndose los inmigrantes ilegales y otras personas apátridas no reconocidas

\footnotetext{
48 En el caso de la normatividad en España es un plazo de 20 días.

49 Realizado en Bruselas el 29 de mayo del 2000.

50 En algunos países como Bélgica, Grecia, Francia, Letonia, Polonia y Reino Unido los derechos a la asistencia legal y el reembolso de los costos pueden depender de los ingresos de una persona. En otros como Bulgaria, Croacia y Rumania dependen del tipo de delito a denunciar.

51 Incluso en el caso de España podrá ser adelantado no solo por las víctimas, sino por asociaciones de víctimas.
} 
por el Estado miembro, que pueden ser víctimas de un delito en un país, pero no tener derecho a asistencia jurídica. ${ }^{52}$

Por otro lado, se encontró otro argumento fundamental que aborda La Directiva entre sus disposiciones para garantizar la participación de las víctimas en el proceso: la previsión de normas para proteger sus intereses cuando vayan a intervenir en un procedimiento de justicia reparadora, ${ }^{53}$ de tal manera, como se ha interpretado en la literatura jurídica, que se promueva un diálogo restaurativo entre todas las partes implicadas. Esto supone una concepción radicalmente distinta del modo de entender la participación en el proceso no solo de la víctima, sino también del infractor e incluso de la comunidad. ${ }^{54}$

La mediación penal, como procedimiento de justicia restaurativa, puede ser de gran ayuda para satisfacer los intereses de las víctimas, por lo que también se requiere la adopción de garantías de protección contra cualquier riesgo de victimización, intimidación o represalias que pudieran sufrir con ocasión de su participación en este. Resulta entonces fundamental que los organismos que vayan a cumplir estas funciones establezcan entre sus prioridades satisfacer los intereses y necesidades de las víctimas; reparar los daños que se le puedan haber ocasionado a consecuencia del delito, e impedir cualquier otro tipo de perjuicios. De tal manera, a la hora de remitir cualquier asunto penal a los servicios de justicia restaurativa o de llevar a cabo un proceso de este tipo, se recomienda que se tomen en consideración factores como la naturaleza y gravedad del delito cometido, el grado de los daños y perjuicios causados, la violación reiterada de la integridad física, sexual o psicológica de la víctima, así como los desequilibrios de poder, su edad, madurez o capacidad intelectual, que puedan limitar o reducir su libertad para llegar a un acuerdo con pleno

\footnotetext{
$52 \mathrm{Al}$ respecto puede consultarse: Encarnación La Spina, "Buenas/malas familias migrantes y su integración en la Unión Europea", Migraciones Internacionales 10, no. 36 (2019); José María Porras Ramírez, "El sistema europeo común de asilo y la crisis de los refugiados. Un nuevo desafío de la globalización", Revista de Estudios Políticos, no. 175 (2017): 207234; Marta Graciela Cabeza, "La crisis migratoria en la Unión Europea: algunas claves para su análisis multidi-mensional", La Unión Europea en Contexto de Crisis, (2018), 56.

53 Artículo 12 de la Directiva 2012/29/UE del 25 de octubre de 2012.

54 Josep María Tamarit Sumalla, “¿Hasta qué punto cabe pensar victimológicamente el sistema penal?" en Estudios de Victimologia. Actas del I Congreso Español de Victimología, coordinado por Josep María Tamarit Sumalla, (Valencia: Tirant lo Blanch, 2005), 38.
} 
conocimiento de causa y a producirle graves perjuicios en sus intereses, que justifican la prohibición de acudir a la justicia restaurativa en estos casos.

Como se puede observar, La Directiva reconoce con mayor determinación y contundencia las posibilidades que tienen las víctimas de participar al interior del proceso penal a pesar de la discrecionalidad que le otorga a los Estados miembros de desarrollar lo plasmado en sus legislaciones.

Respecto al TEDH, ha desarrollado una gran jurisprudencia frente a los derechos de las víctimas relacionados con la obligación que tienen los Estados de investigar y sancionar las graves violaciones a los derechos humanos, en un sentido procesal y material - por ejemplo: deber de desarrollar una investigación eficaz, tipificar determinadas conductas_- ${ }^{55}$ aunque se ha dejado claro que la víctima no tiene un derecho absoluto a participar en el proceso penal. ${ }^{56} \mathrm{El}$ TEDH reconoció en el caso Pérez. c. Franci $^{57}$ la figura de parte civil en el interior del proceso penal, generando un enfoque nuevo tomando el artículo 6 del Convenio Europeo de Derechos Humanos, con el propósito de proteger "su lugar adecuado en los procedimientos penales". ${ }^{58}$ La consecuencia que se obtiene de esta decisión es que la víctima tiene derecho a ser oída públicamente, dentro de un plazo razonable y de forma equitativa en un juicio imparcial. Lo que se debe manifestar es que deben existir condiciones de igualdad entre el acusado y la víctima, ya que el TEDH ha evidenciado en varias sentencias ${ }^{59}$ que actualmente existe una triangulación del proceso penal y esa situación eventualmente puede afectar la igualdad de armas.

A su vez, el TJUE ha tenido que pronunciarse respecto a este tema principalmente ante demandas prejudiciales de interpretación del derecho comunitario, más aún con la entrada en vigor del Tratado de Ámsterdam en 1999 sobre asuntos referentes a cooperación penal. En 2005, en la Sentencia C-105/03 del 16 de junio, conocida como el Caso Pupino, y con ocasión de la existencia de la Decisión Marco, expresó que la práctica de pruebas anticipadas practicadas a favor de las víctimas y personas más

\footnotetext{
55 Al respecto se puede consultar TEDH. Caso Opuz.c. Turquía, sentencia de 9 de junio de 2009 y TEDH. Caso O'keeffe c. Irlanda, sentencia del 28 de enero de 2014.

56 Cfr. TEDH. Caso Leuska y otros c. Estonia, sentencia del 7 de noviembre de 2017.

57 TEDH. Caso Pérezc. France, sentencia del 12 de febrero de 2004.

58 Ibíd.

59 Se puede encontrar: TedH. Caso Van Doorson c. Países Bajos, 26 de marzo de 1996 y Caso S.N. c. Suecia, 2 de julio de 2002.
} 
vulnerables deben ser interpretadas de conformidad con la normatividad comunitaria, bajo las limitaciones propias del derecho de contradicción que deben tener todas las pruebas. ${ }^{60}$ En sentido similar se pronunció, posteriormente, en el Caso C-404/07 Katz c. István Roland Sós. ${ }^{61}$

Como se puede observar, el TJuE no le da relevancia al estatuto formal-procesal de la víctima si es parte o no del proceso, como al derecho sustancial de contribuir con pruebas a pesar de alguna imposibilidad formal. Lo que resulta claro es que si bien es cierto la normatividad referente al proceso penal como se ha visto tiene por objetivo generar mejores condiciones a la víctima, no puede dejar de lado al procesado que, para los autores, resulta ser el protagonista del proceso penal. Se encuentra entonces en cabeza de los Estados al momento de adoptar las normas considerar todos estos matices.

\subsection{Reparación de daños e indemnización de perjuicios}

El aspecto referente a la reparación e indemnización de los daños y perjuicios ocasionados por un delito se ha convertido en una cuestión de vital importancia en materia penal, al tener en cuenta que en principio la víctima no tiene un estricto interés en que el perpetrador del delito sea sancionado o sea declarado culpable, sino que busca la indemnización de los perjuicios que le ha ocasionado el acto punible. Por ello se ha considerado a la reparación como la reacción adecuada para solucionar el conflicto desde una perspectiva formal y material, no solo compensa al injusto y restituye la validez de la norma, sino que cumple con una función de protección de bienes jurídicos y de esa manera logra satisfacer las prioridades de las víctimas. ${ }^{62}$

Teniendo en cuenta lo anterior, la UE mediante la Decisión Marco y la Directiva 2004/80/CE del 29 de abril de 2004 del Consejo, referente a la indemnización a las víctimas de delitos, adoptó los aspectos relativos

60 Al respecto se puede consultar TJuE. Caso C-105/03 - Caso Pupino. Sentencia de 16 de junio de 2005. par. 61.

61 Al respecto se puede consultar TJUE. Caso C-404/07 György Katz. c. István Roland Sós. Sentencia de 9 de octubre de 2008. par. 48-50.

62 Pablo Galain Palermo, "La reparación del daño en un sistema penal funcional a las necesidades de la política criminal”, en Estudios de Victimología. Garantías y derechos de las víctimas especialmente vulnerables en el marco jurídico de la Unión Europea, coordinado por Monserrat de Hoyos Sancho, (Valencia: Tirant lo Blanch, 2013): 582. 
a la reparación e indemnización de estas. Desafortunadamente, con posterioridad se logró determinar que el grado de aplicación por parte de los Estados miembros de estos dos actos legislativos ha sido irregular. A pesar de que la Directiva 2004/80/CE sobre indemnización ha sido incorporada en la gran mayoría de los Estados miembros, se encontró que la justicia restaurativa estaba permitida en 21 Estados, en 5 Estados no se contaba con guías referentes a la reparación y en 12 no se contaba con la información suficiente para hacerla efectiva (traducción libre). ${ }^{63}$

Para solventar estas necesidades, se estableció como principal objetivo para los Estados que "Cuando se prestan servicios de justicia restaurativa, se apli[quen] ciertos estándares mínimos en todos los Estados miembros" (traducción libre). ${ }^{64} \mathrm{Si}$ bien es cierto que los derechos explicados anteriormente establecen mecanismos diferentes de reparación a las víctimas distintos a los pecuniarios, La Directiva reconoce en su artículo 16 el derecho de las víctimas a obtener en un plazo razonable y en el curso del proceso penal una resolución relativa a la indemnización de los daños y perjuicios sufridos por parte del infractor, salvo cuando el derecho nacional de cada Estado estipule que debe ser acordada en otro tipo de procedimiento judicial, en cuyo caso deberá promover las medidas necesarias para que sea efectuada de manera adecuada.

A pesar de que en algunos países hay disposiciones para que un juez imponga condiciones específicas para garantizar que la víctima reciba una indemnización — por ejemplo, Bélgica o Francia- o medidas donde el Estado puede congelar o confiscar la propiedad de la persona acusada si existe el temor de que no compensará a la persona agraviada — Bulgaria-, la experiencia ha demostrado que resulta casi imposible hacer efectiva esa indemnización con cargo a los bienes del procesado por encontrarse en situación de insolvencia debidamente probada, no haber sido identificado o estar en paradero desconocido.

Por ello se hace imprescindible en estos casos acudir a las disposiciones establecidas en la Directiva 2004/80/CE sobre indemnización a las víctimas de delitos, con el fin de facilitarles subsidiariamente el acceso a una compensación económica justa y adecuada a cargo de fondos públicos, con independencia del territorio de la UE en que se haya cometido el delito.

\footnotetext{
63 Cfr. $\operatorname{COM}(2011) 274$ final, 3.

64 Ibíd., 8.
} 
No obstante, se ha considerado que esta directiva debería ser revisada con el fin de establecer una legislación que regule los principales extremos para acceder a dicha indemnización, principalmente en lo referente al ámbito territorial y personal, tipo de daños cubiertos, criterios para determinar su importe, previsión de anticipos, procedimientos y requisitos para su solicitud, o de introducir ciertos criterios restrictivos para su concesión, situaciones imprescindibles para corregir las grandes diferencias aún existentes entre los sistemas indemnizatorios vigentes en los distintos Estados miembros y asegurar una igualdad de trato para todas las víctimas independientemente del territorio de la UE donde se haya cometido el delito. ${ }^{65}$

Por otro lado, al estar relacionado con ese asunto y la finalidad de procurar el total resarcimiento de las víctimas con ocasión de su intervención en las actuaciones judiciales, la Directiva 2012/29/UE también les reconoce su derecho a obtener el reembolso de los gastos que hayan afrontado por su participación activa en el proceso penal ${ }^{66}$ y la restitución de los bienes que les hayan sido incautados, ${ }^{67}$ tal como se enunció anteriormente, remitiéndose obligatoriamente en ambos casos a lo dispuesto en su respectiva legislación nacional para regular las condiciones en que haya de efectuarse dicho reembolso o restitución.

Es esencial manifestar que la reparación e indemnización son relevantes. Sus formas y mecanismos han sido impulsados y desarrollados de mejor manera por parte de los tribunales internacionales principalmente frente a casos referentes a crímenes contra derechos humanos, en los que se ha logrado que la reparación de las víctimas de los delitos no solo tenga una naturaleza pecuniaria o económica, sino herramientas como las garantías de no repetición, rehabilitación y medidas de satisfacción.

Es por ello, que el TEDH se ha limitado ya sea a emitir un juicio declarativo de la existencia de la violación con el resultado de que el demandante obtenga una sentencia favorable a sus pretensiones, que no logra otra reparación diferente a los gastos del litigio. El TEDH (a diferencia

65 Cfr. Manuel José García Rodríguez, "El Nuevo estatuto de las víctimas del delito en el proceso penal según la Directiva Europea 2012/29/UE, de 25 de octubre, y su transposición al ordenamiento jurídico español”, Revista Electrónica de Ciencia Penaly Criminología (en linea), no. 18-24 (2016): 1-84, http://criminet.ugr.es/recpc/18/recpc18-24.pdf

66 Artículo 14 de la Directiva 2012/29/UE de 25 de octubre de 2012.

67 Artículo 15 de la Directiva 2012/29/UE de 25 de octubre de 2012. 
de lo que sucede con la Corte Interamericana de Derechos Humanos) tampoco suele dar razones de la cantidad que otorga como indemnización por daños morales, señalando únicamente consideraciones de equidad. Incluso suele conceder una suma global sin especificar qué corresponde por daños morales y qué por daños y perjuicios. ${ }^{68}$

A pesar de que la indemnización y la reparación son incapaces de restaurar o reemplazar los derechos y el daño causado, incluso se han considerado como sustituto inadecuado, estas sirven para afirmar un respeto público por la víctima y es un reconocimiento público de la falta cometida. De ahí la necesidad de que en el ámbito de las indemnizaciones sea necesaria e imprescindible la equidad puesto que la incapacidad de lograr una consistencia en las indemnizaciones tiende a dañar la confianza general en la justicia y la integridad del sistema de derechos humanos.

\subsection{Protección de su seguridad e intimidad}

Un aspecto fundamental que debe procurarse a favor de las víctimas es otorgarles la suficiente protección para evitar que se expongan a situaciones fácticas posteriores de mayor gravedad frente a quien cometió el delito, ya sea con intimidaciones o con nuevos actos delictivos. Justamente la Comisión Europea mediante la propuesta de La Directiva, ${ }^{69}$ al momento de determinar las necesidades de las víctimas, consideró que no se cubre su protección (traducción libre). ${ }^{70}$

Para procurar este objetivo, la Comisión estableció que mediante una serie de objetivos se podría garantizar en mayor medida la seguridad e intimidad de la víctima, para ello propuso que al momento de adoptar normas por parte del Parlamento Europeo y el Consejo se tenga en cuenta

cuando se solicitan, y se basan en el reconocimiento mutuo, se brindan medidas de protección a las personas que ya se están beneficiando de una medida de protección, cuando viajan o se trasladan al extranjero (...) El contacto entre el agresor y la víctima se minimiza durante los

68 Luis Miguel Cruz, "La reparación de las víctimas en el Convenio Europeo de Derechos Humanos”, Revista Española de Derecho Internacional LXII, (2010): 89-117.

69 $\operatorname{COM}(2011) 274$ final.

70 Ibíd., 2-3. 
procedimientos. Cualquier nuevo tribunal se construye con áreas de espera separadas (traducción libre). ${ }^{71}$

La idea de estos objetivos es evitar que la víctima pierda los beneficios o la protección en el momento en que se desplaza o viaja al extranjero, y evitar la victimización secundaria, entendida como la "exposición de las víctimas a ulteriores situaciones dolorosas, más allá de la que constituyó el hecho mismo de su victimización primaria", ${ }^{72}$ esta última situación con mayor relevancia en personas vulnerables como son las mujeres y los niños.

Tristemente la Comisión (traducción libre) ${ }^{73}$ encontró que no todos los Estados contaban con estas medidas. Dentro de los estudios que se realizaron se logró determinar el grado de cumplimiento así: i) para el caso de protección policial a víctimas y familiares, 22 Estados contaban con este precepto; ii) frente a la custodia preventiva hacía el delincuente, 22 Estados cumplían; iii) 8 Estados contaban con un equipo dedicado a la protección; iv) reubicación de víctimas, 19 Estados cumplían; v) instalaciones en los juicios, 17 Estados; vi) medidas para prevenir que los delincuentes revictimicen, 14 Estados, y vii) derecho a mantener en anonimato a las víctimas, 14 Estados. Resulta excesivamente grave esta situación, puesto que incluso en algunos Estados no se contaba con obligaciones respecto a este punto. ${ }^{74}$

Ahora bien, desde la perspectiva de la cooperación internacional en materia penal, los Estados se encuentran obligados a dar aplicación estricta y generar medios para impedir que se vea afectada la seguridad e integridad de todas las víctimas.

Posteriormente, La Directiva, siguiendo los pasos de la norma anterior, estableció en su artículo 18 la obligación que tienen todos los

\footnotetext{
71 Ibíd., 8.

72 María del Pilar Martin Ríos, Victima y justicia penal, (Barcelona: Atelier, 2012), 440.

73 Cfr. $\operatorname{COM}(2011) 274$ final, 10.

74 Aunque la Directiva 2011/99/UE estableció “(...) normas que permiten que una autoridad judicial o equivalente de un Estado miembro en el que se haya adoptado una medida de protección destinada a proteger a una persona contra actos delictivos de otra que puedan poner en peligro su vida, su integridad física o psicológica y su dignidad, su libertad individual o su integridad sexual, dicte una orden europea de protección que faculte a una autoridad competente de otro Estado miembro para mantener la protección de la persona en el territorio de ese otro Estado miembro, a raíz de una infracción penal o una presunta infracción penal con arreglo al Derecho nacional del Estado de emisión".
} 
Estados de adoptar las medidas necesarias para proteger la seguridad de las víctimas y sus familiares del riesgo de sufrir cualquier tipo de represalias, intimidación o victimización secundaria con ocasión de su participación en el proceso penal.

En primer lugar, las medidas de protección básicas incluirán en todo caso brindar protección física para evitar su contacto con el procesado en las dependencias donde se adelante el proceso penal y aquellas otras orientadas a minimizar el riesgo de que puedan sufrir afectación psicológica o emocional con la aplicación del interrogatorio $;^{75}$ incluso se prevé que sean interrogadas sin demora alguna tan pronto hayan presentado su denuncia ante las autoridades competentes, que el número de declaraciones sea el mínimo posible y que solo se celebren cuando sean estrictamente necesarias a los fines del proceso penal. ${ }^{76}$ Se les brinda a su vez la posibilidad de estar acompañadas por su representante legal o cualquier otra persona de su elección.

El segundo nivel de protección está destinado a las víctimas que presentan necesidades especiales de protección, en el entendido que exclusivamente tiene relevancia para determinadas políticas y medidas de protección. La Directiva no define ni clasifica las víctimas especialmente vulnerables, ${ }^{77}$ pero establece una situación especial para ellas, de tal manera que puedan ser objeto de una evaluación puntual e individual para determinar sus necesidades especiales de protección ${ }^{78}$ y las medidas de las que puedan beneficiarse durante el curso del proceso penal, teniendo en cuenta sus características personales, el tipo o naturaleza del delito y sus circunstancias. Se debe determinar si se está frente a una situación de violencia de género, delitos por motivos de odio o aquellas víctimas en estado o condición de discapacidad.

Por su parte, dado que entre las víctimas con especiales necesidades de protección se encuentran los menores de edad, también para ellos se contemplan una serie de medidas específicas durante su participación

\footnotetext{
75 Al respecto se puede consultar TEDH. Caso Y. c. Eslovenia, sentencia del 28 de mayo de 2015.

76 Véase Tedh. Caso M. y M. c. Croacia, sentencia del 3 de septiembre de 2015.

$77 \mathrm{Al}$ respecto se puede consultar Joaquín Delgado Martín, "La tutela judicial de las personas vulnerables" en Garantías procesales en los procesos penales en la Unión Europea, coordinado por C Arangüena Fanego, (Valladolid: Lex Nova, 2007), 271-285.

78 Artículo 22 de la Directiva 2012/29/UE de 25 de octubre de 2012.
} 
en las actuaciones judiciales, ${ }^{79}$ que reproducen las previstas en otros instrumentos normativos suscritos en el marco regional europeo como el artículo 15 de la Directiva 2011/36/UE del 5 de abril de 2011 relativa a la prevención y lucha contra la trata de seres humanos y a la protección de las víctimas, por la que se sustituye la Decisión Marco 2002/629/ JAI del Consejo ${ }^{80}$ y el artículo 20 de la Directiva 2011/92/UE del 13 de diciembre de 2011 relativa a la evaluación de las repercusiones de determinados proyectos públicos y privados sobre el medio ambiente. ${ }^{81}$ En ella se encuentra como novedoso que sus interrogatorios puedan ser grabados en video y utilizados como elementos de prueba en el proceso penal, para evitarles los graves perjuicios que podría acarrearles su declaración en el acto del juicio oral, que permite en todo caso el derecho al debido proceso y defensa del procesado. ${ }^{82}$

La forma en que se garantizan estos derechos de protección se ve facilitada en la mayoría de los casos por el cumplimiento del artículo 22 de La Directiva. Para el caso, Alemania, Lituania y Eslovenia han quedado fuera de esta evaluación ya que no está claro en sus textos legales si este artículo se ha transpuesto y no se ha obtenido ninguna verificación de las autoridades nacionales.

Como se puede observar, se lograron determinar una serie de medidas en procura de la protección de las víctimas que generan mayor seguridad y brindan posibilidades de impedir una revictimización o poner en peligro la integridad de estas; los Estados deben establecer mayores controles y políticas en pro de lograr este objetivo.

$79 \mathrm{Al}$ respecto se puede consultar TEDH. Caso D.M.D. c. Rumania, sentencia del 3 de octubre de 2017; y TEDH. Caso A y B. c. Croacia, sentencia del 20 de junio de 2019.

80 Doue L 10115 de abril de 2011, 1-11.

81 DOUE L 2628 de enero de 2012, 1-21.

82 A este respecto la jurisprudencia del TEDH Caso S.N. c. Suecia sentencia del 2 de julio de 2002 reconoce que la utilización como prueba de estas declaraciones obtenidas en la fase sumarial no es en sí misma incompatible con los apartados 1 y $3 . d$ del artículo 6 del Convenio Europeo para la Protección de los Derechos Humanos y Libertades Fundamentales, siempre que exista una causa legítima que impida esa declaración en el juicio oral y que se hayan respetado los derechos de defensa del acusado. 


\section{Conclusiones}

El ordenamiento jurídico de la UE en desarrollo de lo establecido en el TFUE ha buscado con la emisión de diversa normatividad armonizar el proceso penal, procurando un claro equilibrio entre las partes, donde se puedan consagrar derechos para las víctimas, por un lado, y para los acusados o procesados, por otro, que den las garantías procesales para cada caso. Además de obtener mejoras en el proceso de evitar una doble victimización en los Estados.

En ese caso, la evolución entre la Decisión Marco hacia La Directiva evidencia que esta última resulta ser más garantista y con más potestades que demuestran una mayor eficacia. Esto pone de manifiesto una voluntad de otorgar una mayor protección a las víctimas, demostrándose su importancia para el ordenamiento jurídico de la UE. Además, el desarrollo de derechos donde las víctimas puedan desplegar facultades procesales les da su lugar correspondiente; lejos queda la teoría clásica en la que el lesionado se encontraba olvidado y sin protección alguna, incluso cuando quien percibe el delito y lo sufre directamente es quien, en búsqueda de sanar la herida que genera en la sociedad la ocurrencia de actos delictivos, debe poder ejercer mecanismos que le permitan superar de una mejor manera lo que ha padecido.

Así, el desarrollo de garantías procesales y derechos a favor de las víctimas de delitos requiere una mayor cooperación jurídica internacional, en la medida en que se de la asistencia mutua entre Estados y la posición que tenga la víctima dentro del proceso penal en cada país.

Por su parte, el Consejo de Europa mediante normas soft law ha desarrollado los derechos de las víctimas; la intervención del TEDH conduce a una nueva línea de actuación en algunos casos específicos en los que están en juego graves violaciones y la evolución jurisprudencial puede llevar a una mayor y mejor aplicación de los derechos de las víctimas hacia el futuro, mediante la imposición de mayores obligaciones y deberes a los Estados.

A pesar de lo anterior, es necesario hacer más para garantizar que las víctimas conozcan sus derechos. A pesar de los cambios introducidos en los Estados, las víctimas a menudo desconocen aún sus facultades, lo que desmejora la eficacia de La Directiva, además de las leyes, las cuales deberían estar disponibles con material que resuma los atributos de las víctimas en un formato de fácil acceso, así como conocer a dónde pueden acudir para obtener ayuda para ejercerlos. 
Por su parte, también es necesario aumentar la conciencia sobre los derechos de las víctimas entre la población en general, fundamentalmente entre familiares y amigos a quienes las víctimas acuden a menudo en primera instancia. Las autoridades judiciales, la policía y las organizaciones de apoyo a las víctimas tienen un papel particularmente importante que desempeñar en la promoción de dichos derechos según La Directiva, pero se podría hacer más para ayudar a familiares y amigos a comprender los problemas que enfrentan las víctimas de delitos y el apoyo que pueden brindar a los individuos interesados.

Adicionalmente, en cuanto a la aplicación práctica, la gran mayoría de las disposiciones de La Directiva parecen haber sido incorporadas adecuadamente en casi todos los Estados miembros. No obstante, el modo en que estas disposiciones se han integrado en los procedimientos administrativos son diferentes en cada uno. A modo de ejemplo, un aspecto en el que la mayoría de los Estados ha mostrado importantes avances, tanto a nivel legislativo como administrativo, es la evaluación individual de las necesidades de las víctimas. Por su parte, un punto que aún no está del todo claro es la aplicación de las disposiciones de La Directiva en lo referente a las víctimas de aquellos delitos que ocurren en un Estado miembro distinto del lugar de residencia habitual de la víctima, donde los profesionales no saben en todos los casos qué hacer.

Infortunadamente la Comisión Europea aún no ha evaluado la transposición y aplicación de La Directiva, aunque, de conformidad con su artículo 29, debía informar al respecto en noviembre de 2017. Cabe añadir que La Directiva ha mostrado dificultades para integrar la intervención de la UE y la necesidad de contar con unas normas mínimas en un contexto de tradiciones nacionales muy diferentes, así como la falta de recursos financieros destinados a su implementación. Por ello resulta trascendental que se emita este pronunciamiento, para determinar en qué medida la equivalencia de derechos en toda la UE está beneficiando a los ciudadanos y residentes que son víctimas de delitos.

\section{Referencias}

Blázquez Peinado, María Dolores. "La Directiva 212/29/UE ¿Un paso adelante en materia de protección a las víctimas en la Unión Europea?" Revista de Derecho Comunitario Europeo 17, no. 46 (2013): 897-934.

Aguilera, Marien. "Justicia penal y Unión Europea: un breve balance en clave de derechos". Diario La Ley, no. 8883 (2016). 
Bock, Stefanie. "Das europäische Opferrechtspaket: zwischen substantiellen Fortschritt und blinden Aktionismus", zIS 8, (2013): 201-11.

Cabeza, Marta Graciela. "La crisis migratoria en la Unión Europea: algunas claves para su análisis multidi-mensional”, en La Unión Europea en Contexto de Crisis, editado por María Victoria Álvarez y Marta Cabeza, 56-81. Rosario: UNR Editora, 2018.

Christie, Nils. "The Ideal Victim", en From Crime Policy to Victim Policy, editado por E. A. Fattah, 17-30. London: Palgrave Macmillan, 1986.

Cruz, Luis Miguel. "La reparación de las víctimas en el Convenio Europeo de Derechos Humanos". Revista Española de Derecho Internacional LXII, (2010): 89-117.

de Hoyos Sancho, Montserrat. "El tratamiento procesal de las víctimas especialmente vulnerables en los últimos instrumentos normativos aprobados en la Unión Europea", en Garantías y derechos de las victimas especialmente vulnerables en el marco jurídico de la Unión Europea, coordinado por Montserrat de Hoyos Sancho, 49-74. Valencia: Ed. Tirant lo Blanch, 2013.

de Hoyos Sancho, Montserrat. "Reflexiones sobre la Directiva 2012/29/ UE, por la que se establecen normas mínimas sobre los derechos, el apoyo y la protección de las víctimas de delitos, y su transposición al ordenamiento español". Revista General de Derecho Procesal, no. 34 (2014): 1-53.

Delgado Martín, Joaquín., "La tutela judicial de las personas vulnerables", en Garantías procesales en losprocesos penales en la Unión Europea, coordinado por C. Arangüena Fanego, 271-85. Valladolid: Lex Nova, 2007.

Faggiani, Valentina. "El derecho a la información en los procesos penales en la UE: la Directiva 2012/13/UE, de 22 de mayo de 2012". Revista General de Derecho Procesal, no. 30 (2013): 1-18.

Galain Palermo, Pablo., "La reparación del daño en un sistema penal funcional a las necesidades de la política criminal", en Estudios de Victimología. Garantías y derechos de las víctimas especialmente vulnerables en el marco jurídico de la Unión Europea, coordinado por Monserrat de Hoyos Sancho, 577-89. Valencia: Tirant lo Blanch, 2013.

García Rodríguez, Manuel José. "El nuevo estatuto de las víctimas del delito en el proceso penal según la Directiva Europea 2012/29/ UE, de 25 de octubre, y su transposición al ordenamiento jurídico español". Revista Electrónica de Ciencia Penal y Criminología (en línea), no. 18-24 (2016): 1-84. Recuperado de http://criminet.ugr.es/ recpc/18/recpc18-24.pdf 
Gómez Colomer, Juan Luis. "Víctima del delito y Europa". Revista Teoría y Derecho, no. 17 (2015): 100-120.

Grigoriev, Iván. Role of the European Court of Justice in the Third Pillar: Does Not it Grow Too Fast?, Higher School of Economics, documento de investigación No. WP BRP 11/IR/2014. Recuperado de https:// papers.ssrn.com/sol3/papers.cfm?abstract_id $=2543443$

Jimeno Bulnes, Mar. "Perspectiva actual del espacio judicial europeo en materia civil y penal: Especial incidencia de la jurisprudencia del Tribunal de Justicia", en Nuevas aportaciones al espacio de libertad, seguridad y justicia bacia un derecho procesal europeo de naturaleza civily penal, coordinado por Mar Jimeno Bulnes, 1-46. Granada: Comares, 2014. La Spina, Encarnación. "Buenas/malas familias migrantes y su integración en la Unión Europea". Migraciones Internacionales 10, no. 36 (2019). Llorente Sánchez-Arjona, Mercedes. "Las víctimas en el espacio judicial europeo: estudio de la directiva 2012/29/UE, de 25 de octubre de 2012". Revista de Estudios de la Justicia, no. 22 (2015): 119-141.

López, Alejandro. "Crimen transfronterizo y determinación de la jurisdicción en el espacio de libertad, seguridad y justicia: ¿Hacia una nueva normativa sobre resolución de conflictos de ejercicio de jurisdicción penal?". Revista de Estudios Europeos, no. 71 (2018): 220-233.

Martin Ríos, María del Pilar. Victima y justicia penal. Barcelona: Atelier, 2012. Martínez, Gema Varona. "El impacto de la política victimal de la Unión Europea en el sistema penal español: Estudio particular de los efectos reales de la Directiva 2012/29/UE sobre derechos de las víctimas de delitos". En Adaptación del derecho penal español a la politica criminal de la Unión Europea, 545-91. Pamplona: Aranzadi, 2017.

Mitsilegas, Valsamis. EU Criminal Law. Oxford: Hart publishing, 2009.

Mitsilegas, Valsamis, Monar, Jorge, y Rees, Wyn. The European Union and Internal Security. Guardian of the People? Londres: Palgrave Macmillan, 2003.

Oromí I Vall-Llovera, Susana. "Víctimas de delitos en la Unión Europea. Análisis de la Directiva 2012/29/UE". Revista General de Derecho Procesal, no. 30 (2013): 1-31.

Pemberton, Antony, Willem Winkel, Frans, \& Groenhuijsen, Marc. “Taking Victims Seriously in Restorative Justice". International Perspectives in Victimology 3, no. 1 (2007): 4-14.

Pereira Puigvert, Silvia. "Normas mínimas para las víctimas de delitos: análisis de la Directiva 2012/29/UE. Especial referencia al dere- 
cho de información y apoyo". Revista General de Derecho Europeo, no. 30 (2013).

Pérez Rivas, Natalia. "Normas mínimas de los derechos básicos de las víctimas de delitos en Europa". Revista de derecho de la Universidad de Montevideo, no. 30 (2016): 89-112.

Pérez Rivas, Natalia. "El modelo europeo de estatuto de la víctima". Dikaion 26, no. 2 (2017).

Peyró Llopis, Ana. “La protección de las víctimas en la Unión Europea: la Orden Europea de Protección”. Revista Española de Derecho Europeo, no. 46 (2013): 9-28.

Porras Ramírez, José María. "El sistema europeo común de asilo y la crisis de los refugiados. Un nuevo desafío de la globalización”. Revista de estudios políticos, no. 175 (2017): 207-34.

Rodríguez Puerta, María José. "Sistemas de asistencia, protección y reparación de las víctimas”, en Manual de Victimología, coordinado por Enrique Baca Baldomero, Enrique Echeburúa Odriozola y Josep María Tamarit Sumalla, 407-38.Valencia: Tirant lo Blanch, 2006.

Roxin, Claus., "Sobre o desenvolvimiento do direito procesual penal alemão", en Que futuro para o dereito processual penal? Simpósio em Homenagem a Jorge de Figueredo Dias, por ocasião dos 20 anos do Código de Processo Penal Português, coordinado por Mário Ferreira Monte, Maria Clara Calheiros, Fernando Conde Monteiro. Loureir: Coimbra Editora, 2009.

Sanz-Díez de Ulzurrun Lluch, Marina. "La posición de la víctima en el derecho comparado y en la normativa de la Unión Europea”. Estudios de Derecho Judicial, no. 121 (2007).

Schulte, Jan Markus. Die materielle Wiedergutmachung in Strafverfahren. BadenBaden: Nomos, 2006.

Schünemann, Bernd. "Der Ausbau der Opferstellung im Strafprozess -Flucht oder Segen?”, en Festschrift für Rainer Hamm, 687-700. Berlín: De Gruyter, 2008.

Tamarit Sumalla, Josep María. “¿Hasta qué punto cabe pensar victimológicamente el sistema penal?’. En Estudios de Victimología. Actas del I Congreso Español de Victimología, coordinado por María Josep Tamarit Sumalla, 35-42. Valencia: Tirant lo Blanch, 2005.

Tamarit Sumalla, Josep María. "La política europea sobre las víctimas de delitos”. En Estudios de Victimología. Garantías y derechos de las víctimas especialmente vulnerables en el marco jurídico de la Unión Europea, 
coordinación por Monserrat de Hoyos Sancho, 31-47. Valencia: Tirant lo Blanch, 2013.

Weyembergh, Anne. "The Functions of Approximation of Penal Legislation within the European Union". Maastricht Journal of European and Comparative Law 12, no. 2 (2005): 149-172.

Vacas Fernández, Félix. El terrorismo como crimen internacional. Valencia: Tirant lo Blanch, 2011.

Vervaele, John. "El espacio de libertad, seguridad y justicia", en Estudios de Victimología. Garantías y derechos de las víctimas especialmente vulnerables en el marco jurídico de la Unión Europea. Coord. por Monserrat de Hoyos Sancho: $1^{\mathrm{a}}$ Ed. Valencia: Tirant lo Blanch, 2013. pp. 15-30.

VV. AA. Hacia la unificación del derecho penal. México: INACIPE, 2006. Armenta Deu, Teresa (Coord.). Código de buenas prácticas para la protección de víctimas especialmente vulnerables. Madrid: Editorial Colex, 2011.

\section{Tratados internacionales y documentos obligatorios}

Asociación Portuguesa de Apoyo a las Víctimas (APAV). IVOR Report Implementing victim orientated reform of the criminal justice system in the European Union. Recuperado de https://www.apav.pt/ivor/images/ ivor/PDFs/IVOR-Repot-WebVersion.pdf

Asamblea General. Resolución 2200 A (XXI), de 16 de diciembre de 1966. Comisión al Parlamento Europeo, al Consejo, al Comité Económico y Social Europeo y al Comité de las Regiones. Propuesta de Directiva para reforzar los derechos de las víctimas en la UE. Bruselas 25 de mayo de 2011. COM(2011) 275 final y SEC(2011) 581 final.

Comunicación de la Comisión al Parlamento Europeo, al Consejo, al Comité Económico y Social Europeo y al Comité de las Regiones Refuerzo de los derechos de las víctimas en la UE del 18 de mayo de 2011. $\operatorname{COM(2011)~} 274$ final.

Decisión marco del Consejo 2001/220/JAI, de 15 de marzo de 2001 relativa al Estatuto de la Víctima en el Proceso Penal, Doue L 082 de 22 de marzo de 2001, 1-4.

Directiva del Parlamento Europeo y del Consejo 2011/36/UE, de 5 de abril de 2011, relativa a la prevención y lucha contra la trata de seres humanos y a la protección de las víctimas, DOUE L 10115 de abril de 2011, 1-11. 
Directiva del Parlamento Europeo y del Consejo 2011/99/UE, de 13 de diciembre de 2011 sobre orden europea de protección, DOUE L 33812 de diciembre de 2011, 2-38.

Directiva del Parlamento Europeo y del Consejo 2011/92/UE, de 13 de diciembre de 2011, relativa a la lucha contra los abusos sexuales y la explotación sexual de los menores y la pornografía infantil, DOUE L 33513 de diciembre de 2011, 1-14.

Directiva del Parlamento Europeo y del Consejo 2012/29/UE de 25 de octubre de 2012 por la que se establecen normas mínimas sobre los derechos, el apoyo y la protección de las víctimas de delitos, y por la que se sustituye la Decisión marco 2001/220/JAI, DOUE L 31514 de noviembre de 2012, 57-73.

Parlamento Europeo. Informe sobre la aplicación de la Directiva 2012/29/ UE por la que se establecen normas mínimas sobre los derechos, el apoyo y la protección de las víctimas de delitos (2016/2328(INI)) de 14 de mayo de 2018.

Resolución del Consejo 2011/C187/01 de 10 de junio de 2011 sobre un Plan de trabajo para reforzar los derechos y la protección de las víctimas, en particular en los procesos penales, DOUE C 187 de 28 de junio de 2011, 1-5.

Tratado de Funcionamiento de la Unión Europea.

\section{Jurisprudencia Tribunal Europeo de Derechos Humanos}

TEDH. Caso Van Doorson v. Países Bajos, 26 de marzo de 1996.

TEDH. Caso Conka c. Bélgica. Sentencia del 5 de febrero de 2002

TEDH. Caso S.N. c. Suecia, 2 de julio de 2002.

TEDH. Caso Pérez. c. Francia, sentencia del 12 de febrero de 2004.

TEDH. Caso Opuz. c. Turquía, sentencia del 9 de junio de 2009.

TEDH. Caso O'keeffe c. Irlanda, sentencia del 28 de enero de 2014.

TEDH. Caso Y. c. Eslovenia, sentencia del 28 de mayo de 2015.

TEDH. Caso M. y M. c. Croacia, sentencia del 3 de septiembre de 2015.

TEDH. Caso D.M.D. c. Rumania, sentencia del 3 de octubre de 2017.

TEDH. Caso Leuska y otros c. Estonia, sentencia del 7 de noviembre de 2017. TEDH. Caso A y B. c. Croacia, sentencia del 20 de junio de 2019.

\section{Jurisprudencia Tribunal de Justicia de la Unión Europea}

TJuE. Caso Pupino. Sentencia del 16 de junio de 2005. Asunto C-105/03. 


\section{6}

TJuE. Caso Dell'Orto. Sentencia del 28 de junio de 2007. Asunto C-467/07. TJuE. Caso György Katz c. István Roland Sós. Sentencia del 9 de octubre de 2008. Asunto Caso C-404/07.

TJuE. Caso Eredics. Sentencia del 21 de octubre de 2010. Asunto C-205/09. TJUE. Sentencia del 15 de septiembre de 2011. Asunto C-483/09 y C-1/10. 